\title{
QR
}

Universität Regensburg

COPYRIGHTED MATERIAL

\section{Visual laterality in the domestic horse (Equus caballus) interacting with humans}

\author{
Kate Farmer* $\cdot$ Konstanze Krueger** $\cdot$ Richard W. Byrne* \\ ${ }^{*}$ Centre for Social Learning \& Cognitive Evolution, School of Psychology, University of St Andrews, \\ St Andrews, Scotland KY16 9JP \\ **University of Regensburg Department of Biology I
}

Konstanze Krueger: konstanze-krueger@equine-science.de

Kate Farmer: katefarmer@utanet.at

Correspondence/Author address and contact details:

R W Byrne, Centre for Social Learning and Cognitive Evolution and Scottish Primate Research Group, School of Psychology, University of St Andrews, St Andrews, Fife KY16 8PL, Scotland.

Tel: +44 1334 462051; E-mail : rwb@st-andrews.ac.uk

,The original publication is available at www.springerlink.com‘ Published online: 17 July 2009

http://dx.doi.org/10.1007/s10071-009-0260-x

Volume 13, Number 2, 229-238, DOI: 10.1007/s10071-009-0260-x

\section{Abstract}

Most horses have a side on which they are easier to handle and a direction they favour when working on a circle, and recent studies have suggested a correlation between emotion and visual laterality when horses observe inanimate objects. As such lateralisation could provide important clues regarding the horse's cognitive processes, we investigated whether horses also show laterality in association with people. We gave horses the choice of entering a chute to left or right, with and without the passive, non-interactive presence of a person unknown to them. The left eye was preferred for scanning under both conditions, but significantly more so when a person was present. Traditionally, riders handle horses only from the left, so we repeated the experiment with horses specifically trained on both sides. Again, there was a consistent preference for left eye scanning in the presence of a person, whether known to the horses or not. We also examined horses interacting with a person, using both traditionally and bilaterally trained horses. Both groups showed left eye preference for viewing the person, regardless of training and test procedure. For those horses tested under both passive and interactive conditions, the left eye was preferred significantly more during interaction. We suggest that most horses prefer to use their left eye for assessment and evaluation, and that there is an emotional aspect to the choice which may be positive or negative, depending on the circumstances. We believe these results have important practical implications and that emotional laterality should be taken into account in training methods.

\section{Keywords:}

horse, laterality, eye preference, emotion, vision

\section{Introduction}

Laterality was, for many years, considered to be a uniquely human attribute (for review, see Vallortigara and Rogers 2005) but studies over the last 30 years have provided increasing evidence for lateralisation in other vertebrates, including non-human primates (e.g. Ward 1993, Marchant and McGrew 1991, Lonsdorf and Hopkins 2005, Humle 2009), chicks (Vallortigara and Andrew 1991, Deng and Rogers 1997), and fish, amphibians and reptiles (Bisazza et al. 1998).

In classical horse training it has been observed that most horses lunge more willingly to the left than to the right, and many horses are reluctant, especially at first, to lunge to the right at all (Podhajsky 1967). Traditionally, these lateral biases have been treated by riders and trainers as existing purely on a motor level, roughly equivalent to handedness in people, and motor laterality has been confirmed in formal studies (Murphy et al. 2004; Mc Greevy and Rogers 2004; Williams and Norris 2007; Murphy and Atkins 2008). The tradition of leading and mounting the horse from the left has usually been attributed to former military uses. A soldier would carry his sword on his left leg, making mounting from the left safer. Until recently, it has been assumed that this tradition has simply been carried on by modern equestrians, who continue to mount, lead and handle the horse predominantly from the left because it is deemed "cor- 
rect" (Steinbrecht 1886, Podhajsky 1967). However, Larose et al. (2006) suggest that this may in fact be a matter of mutual convenience, and that horses are lateralised in such a way as to make the left also their preferred side. For this reason we decided to investigate lateralised behaviour specifically in interaction with humans.

Larose et al. (2006) found that a horse's tendency to look at a novel object with its left eye increased with its level of emotionality. Other findings support this observation. Austin and Rogers (2007) found that when a frightening stimulus, an opening umbrella, was presented to the horse in the left monocular field, the flight distance was greater than if the same stimulus was presented on the right; and De Boyer Des Roches et al. (2008) found that the left eye was preferred for objects with positive or negative associations, but the right eye for neutral objects. Asymmetric responses to unfamiliar, inanimate objects have also been widely observed: typically, a horse learns to accept an object on one side, and then behaves as if it had never seen it before when it is presented on the other side. This used to be attributed to a lack of communication between the two hemispheres of the brain, but it is now known that interocular transfer does occur in horses and that an object learned and recognised monocularly is also recognised by the other eye (Hanggi 1999). Alternatively, asymmetric responses may reflect lateral preferences for how objects are examined. Basile et al. (2009) found lateralised responses to auditory signals, with left hemisphere preference for whinnies from familiar neighbour horses, and no preference for members of the same group or completely strange horses.

At present, it is not clear whether the lateralisation observed with inanimate objects also applies in connection with humans, nor whether it is restricted to emotional situations. In order to investigate human related effects on laterality in the domestic horse, we posed four questions:

1.) Is the left-eye preference triggered by the presence of a human, or is it already present in neutral situations?

2.) If there is a left-eye preference particularly in relation to humans, is this a function of training habits?

3.) Are any such laterality effects also present in practical, interactive situations; and if so are they affected by the previous experience and training of the horse?

4.) Is laterality influenced by the nature of the social contact, passive or interactive?

\section{Methods}

Subjects

A total of 55 domestic riding horses were tested. All were riding horses and ponies, of mixed European breeds, between 2 and 23 years old, and all were reported by their owners to be in good health and with normal vision at the time of the tests. One horse, tested in group 2, was found several weeks later to have a neurological condition that eventually affected his eyesight. However, there was no indication of any visual problem at the time of testing, and he gave close to average responses during the tests. All were stabled overnight and regularly turned out in social groups during daylight hours onto grass or dirt paddocks. We tested four groups, as follows, with 10 individuals taking part in both groups 2 and 4 :

Group 1: $N=14$. All had been traditionally trained, that is, usually led from the left and saddled and mounted from the left, and were resident at a single riding stable in Scotland.

Group 2: N=12, (5 geldings and 7 mares, including one pony). All had been trained using techniques designed to build confidence and acceptance of the human on both sides of the horse: led and saddled from both sides, and desensitised to human activity and unfamiliar objects on both sides. These were all resident at a single stabling complex in Austria.

Group 3: N=26, (11 geldings and 15 mares, including four ponies). All had been trained using traditional techniques and were resident at a single riding school in Germany.

Group 4: N=13, (4 geldings and 9 mares). All had been trained using techniques designed to build acceptance of the human on both sides of the horse, and resided at the same stables as those in Group 2, with 10 horses in common to both groups.

\section{Experimental testing areas \\ Test Area 1}

Two chutes were set up at either side of the test area, using jump stands and poles all of identical size, colour and shape. (Fig.1). For group 1 the area was square, approximately $20 \mathrm{~m} \times 20 \mathrm{~m}$, for group 2 it was circular, approximately 15 meters diameter. At the end of each chute was a trough or bucket in which pieces of carrot were placed as an incentive for the horse to enter the chute. The chutes were positioned such that the horse would only see the person in one monocular field while eating the carrot; the wall of the arena obscured the vision of the other eye for group 1 , the fence of the round pen and surrounding foliage obscured it for group 2. As this set-up was unfamiliar to the horses, training trials were conducted for both groups tested with no person present between the chutes. In the training phase, the horses were led to each bucket alternately and allowed to eat the carrot. This was repeated until the horse could be turned loose at the entrance to the test area and it would 


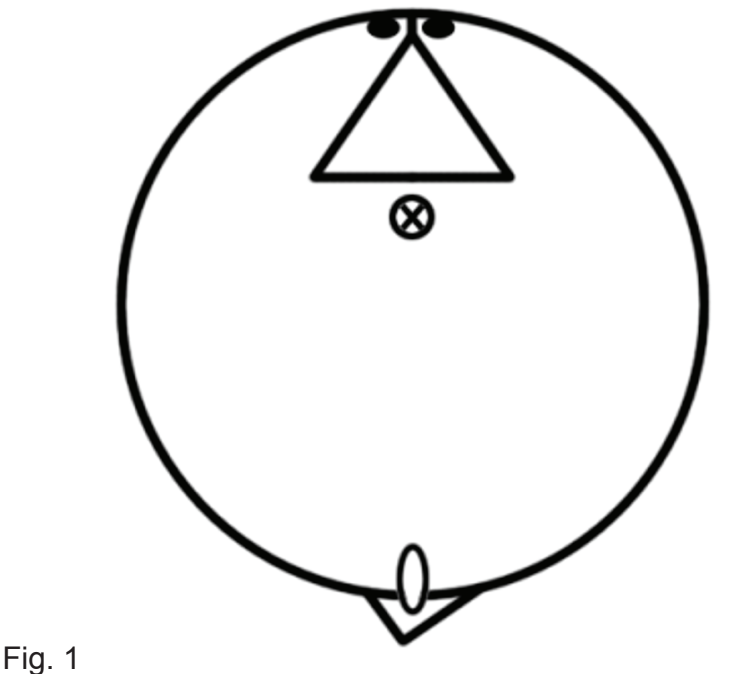

Fig. 1

Test area for experiments 1 and 2, showing how the positioning of the two chutes allowed the horse choice of going to the right or left; the positioning of the known or unknown person for the "human present" conditions; and the release position for the horse, directly opposite the person Key: $\triangle$ Obstacle made of poles and jump stands 0 , Horse released at entrance $\otimes$, Person (in known and unknown person conditions $\checkmark$, Gate $\bullet$, Feed bucket

\section{Statistical analysis}

We applied Generalized Estimating Equations (GEEs) to binomial data, in order to detect possible influences of the test situations, the trials, the horses' sex, and (in experiment 3 ) the direction in which the horse was going immediately before approaching the trainer.

As none of these factors were significant (GEE: $N=$ 1048, test situation: $z=-0.614, p=0.539$, trial no: $z$ $=-1.224, p=0.221$, sex: $z=-1.576, p=0.115$; GEE: $N=316$, rein: $z=1.836, p=0.07$ ), we proceeded by calculating a laterality index for each horse under each condition by dividing the number of left eye responses by the total number of trials. Thus, a laterality index of 0 indicates only right eye responses from that horse, a laterality index of 1 indicates only left eye responses, and 0.5 represents no observed lateral bias. The laterality indices were used to generate frequency tables for the number of horses showing different levels of laterality. The statistical reliability of lateralization for each horse individually, where sufficient data were available, and for the groups used in each experiment, were assessed by comparing the horses' eye preferences with the Binomial Test. Because 3 of the 6 data sets proved not to be normally distributed (Kolmogorov-Smirnov Test, $p<0.05$ ), we applied the non-parametric Wilcoxon matched-pairs, signed-ranks tests for the comparisons of lateralisation in the respective test situations in experiments 1,2 and 4, where we were comparing the same horses under two different conditions. We used a Mann Whitney $U$ Test for experiment 3 , where we were comparing two independent samples. All the data collected were analysed with two tailed tests by using the R statistical environment (2008) or the statistical software SPSS 15.

\section{Experiment 1: Is left-eye preference triggered by the presence of a human or already present in neutral situations?}

We tested the hypothesis that there is no significant preference for either the left or the right eye, in either a human-present or a neutral condition. Horses of group 1 took part in this experiment and test area 1 was used, set up in a 20 metre square section of an enclosed, indoor arena.

The horses were tested under a "neutral condition", with nothing between the chutes and no people in the test area; and a "stranger condition", with a person unknown to the horses standing passively in the middle of the test area between the two chutes (Fig. 1).

\section{Procedure}

Each horse participated in 15 trials under both the neutral and the stranger conditions, and was released alternately from the right and left to make its choice for a feeding bucket, with stranger and neutral trials randomly interspersed, up to the pre-set criterion of 15 trials of each type. The experimenter led the test horses to the test area and released them at the entrance. Thereafter she recorded the data manually and with a video camera, and noted whether the horse entered the chute that would allow it to view the test area with the left eye or the right eye. Six volunteers who had not met the horses before were rotated and randomised equally as the "stranger", so that each horse was confronted with 6 different unknown people. No time limit was set for the horse to approach one or the other chute, but all approached within 30 seconds.

\section{Results}

Under the neutral condition, 13 of the 14 horses preferred the left eye over the right eye (binomial test, $p$ $=0.002$ ) with all but one showing a laterality index of 0.70 or more (see Table 1). The left eye preference was only significant for 4 individual horses (binomial test, each $p=0.04$ ), and the one horse showing a right eye preference had a non-significant laterality index of $0.27(p=0.12)$.

Under the stranger condition, all the horses showed significant individual preferences. The group distribution remained the same, with 13 of the 14 horses preferring the left eye over the right eye and one the reverse; however, laterality indices shifted outwards to the extremes (see Fig. 2). The difference between neutral and stranger conditions was significant (Wilcoxon matched-pairs signed-ranks test $\mathrm{W}+=0, \mathrm{~W}-=$ $36, N=8, p=0.008$ ). 


\begin{tabular}{|c|c|c|c|c|c|c|c|c|c|}
\hline \multicolumn{10}{|c|}{ Table 1 Comparing traditionally and bilaterally trained horses in a passive situation } \\
\hline \multicolumn{5}{|c|}{ Group 1 - traditionally trained } & \multicolumn{5}{|c|}{ Group 2 - bilaterally trained } \\
\hline Horse & \begin{tabular}{|l|} 
Laterality \\
index neutral \\
condition
\end{tabular} & & \begin{tabular}{|l} 
Laterality \\
index stranger \\
condition
\end{tabular} & & Horse & \begin{tabular}{|l|} 
Laterality \\
index neutral \\
condition
\end{tabular} & & $\begin{array}{l}\text { Laterality } \\
\text { index stranger } \\
\text { condition }\end{array}$ & \\
\hline 1 & 0.80 & * & 1.00 & $* * *$ & Kari & 0.23 & & 0.69 & \\
\hline 2 & 0.80 & * & 1.00 & $* * *$ & Offe & 0.62 & & 0.69 & \\
\hline 3 & 0.73 & & 0.87 & $* *$ & Bigsy & 0.62 & & 0.85 & * \\
\hline 4 & 0.73 & & 1.00 & $* \star *$ & Ringo & 0.62 & & 0.77 & \\
\hline 5 & 0.27 & & 0.07 & $* *$ & Ronja & 0.77 & & 0.54 & \\
\hline 6 & 0.67 & & 1.00 & $* * *$ & Melissa & 0.85 & * & 0.62 & \\
\hline 7 & 0.80 & * & 1.00 & $* * *$ & Milka & 0.77 & & 1.00 & $\star * \star *$ \\
\hline 8 & 0.73 & & 0.93 & $* *$ & Ciddley & 0.00 & $* * *$ & 0.08 & $* *$ \\
\hline 9 & 0.73 & & 0.93 & ** & Emily & 0.77 & & 0.69 & \\
\hline 10 & 0.80 & * & 1.00 & $* * *$ & Baron & 0.69 & & 0.62 & \\
\hline 11 & 0.73 & & 0.93 & $* *$ & Keira & 0.31 & & 0.00 & $\star * \star *$ \\
\hline 12 & 0.76 & & 1.00 & $* \star *$ & Nurek & 0.77 & & 1.00 & 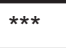 \\
\hline 13 & 0.67 & & 0.87 & $* *$ & & & & & \\
\hline 14 & 0.67 & & 1.00 & *** & & & & & \\
\hline $\begin{array}{l}\text { left prefe- } \\
\text { rent / total } \\
\text { horses }\end{array}$ & $13 / 14$ & & $13 / 14$ & & & 09. Dez & & 10. Dez & \\
\hline $\begin{array}{l}\text { binomial } \\
\text { test }\end{array}$ & $p=0.002$ & & $p=0.002$ & & & $p=0.15$ & & $p=0.04$ & \\
\hline
\end{tabular}

\section{Discussion}

Left eye preference was stronger in the presence of a person, but was also present in a neutral condition in which no person was present. The fact that it remained under the neutral condition could suggest that the left eye preference is not only a question of emotionality, as appeared to be the case in previous studies, but may also be connected with evaluation of the environment. We return to this issue in the general discussion. It is also unclear whether the significantly stronger preference observed with the person present was due to the horses' previous training, in that these horses were used to having the person on

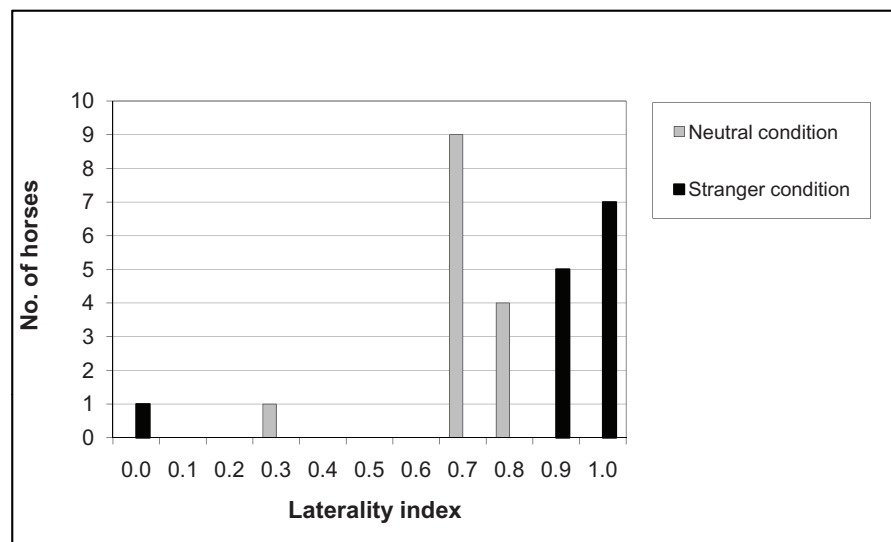

Fig. 2: Frequency distribution of laterality indices (number of left responses divided by total responses) for traditionally trained horses, under neutral conditions and when a stranger is present. A laterality index of 0 indicates only right eye responses from that horse, a laterality index of 1 indicates only left eye responses, and 0.5 represents no observed lateral bias. their left, or due to an emotional reaction to a strange human. Experiment 2 was designed to clarify this issue by comparing the responses to a stranger with responses to a person well known to the horses.

\section{Experiment 2: Is left-eye preference a function of prior training?}

We repeated the procedures of experiment 1 but using a group of 12 horses that had been bilaterally trained to accept and expect people on both sides (group 2). Test area 1 was used, set up in an outdoor, 15 metre diameter circular arena, with which all the horses were familiar. These horses were tested under two conditions, one with a stranger present, and one with a person known to the horses present.

\section{Procedure}

The procedure was similar to experiment 1 , with each horse participating in 13 trials under each condition. As in experiment 1, these trials were also randomised for which condition the horse experienced first, with half the horses being confronted with the known person first, and half the stranger.

The experimenter's role was the same as in experiment 1 , with a person standing passively between the chutes (Fig.1) in every case. Under the "known person" condition, this was an assistant who regularly fed and handled the horses, whereas for the "stranger" condition it was a volunteer who had never met 


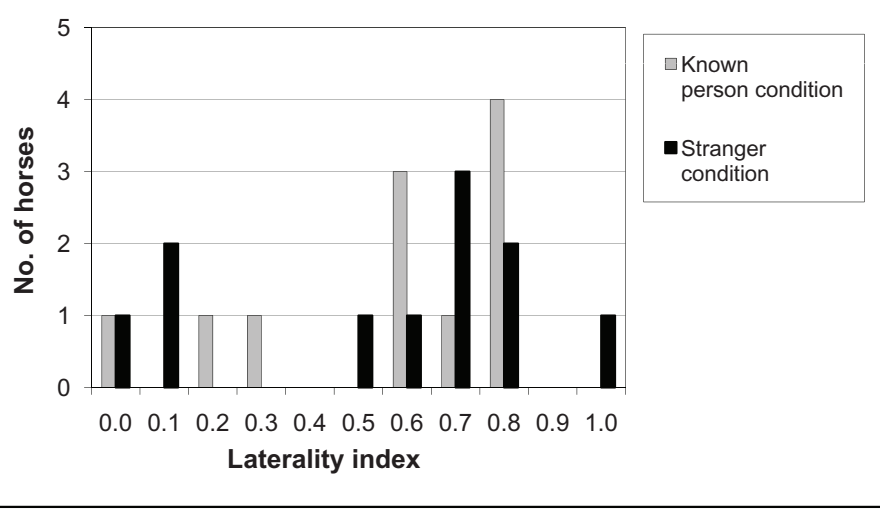

Fig.3: Frequency distribution of laterality indices for bilaterally trained horses, when either a known person or a stranger is present. (Laterality indices as in Fig. 2)

the horses before. Both the known person and the stranger were positioned with their backs to the horses to minimise the chance of them unintentionally influencing the horses' decisions; we are aware of how easily a person's unintentional body language can influence a horse (Pfungst, 1911). Again, no time limit was set for the horse to approach one or the other chute, but all approached within 30 seconds.

\section{Results}

Under the known person condition, there was a non significant tendency for the left eye to be preferred, with 9 of the 12 horses choosing the left eye more often (binomial test, $p=0.146$ ). Only 2 horses were significantly lateralized, 1 to the left and 1 to the right (see Table 1). Under the stranger condition, there was a significant preference for the left eye, with 10 horses of 12 choosing it (binomial test, $p=0.038$ ); of these, 5 horses were significantly lateralised, 3 to the left and 2 to the right. However, in this experiment, there was no significant difference between the known and unknown person conditions (Wilcoxon matched-pairs signed-ranks test: $\mathrm{W}+=32, \mathrm{~W}-=$ $46, N=12, p=0.622$ ).

One horse switched from a right eye preference under the known person condition to a left eye preference under the stranger condition. This was the only instance in our experiments in which a horse changed preference under different conditions.

\section{Discussion}

Comparing these results to those of experiment 1 , the horses trained on both sides showed a weaker left eye response than those trained conventionally. With a stranger, the bilaterally trained horses showed a similar left eye preference to that of the traditionally trained horses under the neutral condition; with a known person, they showed even less preference. The difference between the known person and stranger conditions was not significant. This might have been because the same "unknown person" was used throughout, and could thus have become familiar to

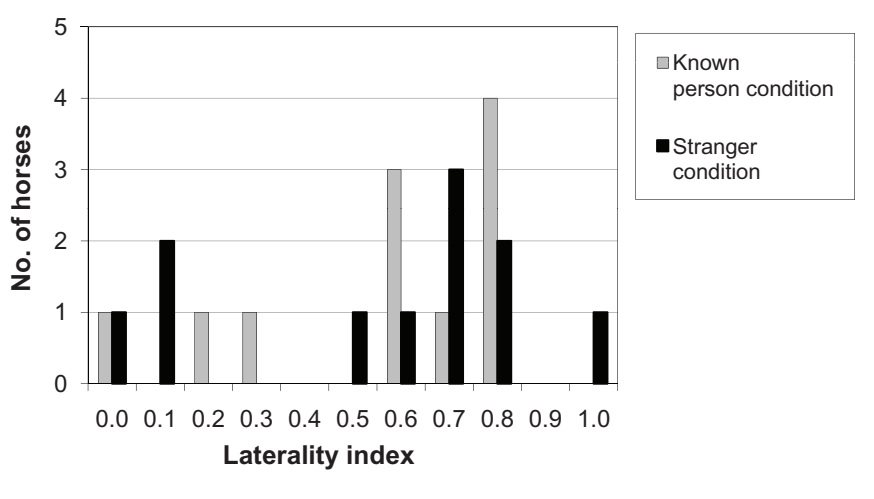

Fig.4: Frequency distribution of laterality indices - interactive test, group 3, traditionally trained horses) and group 4, bilaterally trained horses. (Laterality indices as in Fig. 2)

the horses. However, the GEE analysis did not show a significant effect of the number of the trial, and had familiarisation been the reason, we would have expected the earlier trials to show a stronger left eye preference than the later trials.

Intriguingly, the "right eyed" horses in both groups, although only a very small sample $(\mathrm{N}=3)$, showed the same trends with regard to the right eye, that is to say they showed stronger lateralisation under the stranger condition. As these horses had similar training to the others in their groups, this is further evidence that training is not a factor in the choice of preferred eye.

The weaker left eye preference among the bilaterally trained horses could have been a direct consequence of their training, therefore simply a greater acceptance of a human on the right side; or it could reflect a general lower level of emotionality among these horses, as a result of this training. The latter would be consistent with other studies which have connected left eye preference with emotionality. If the weaker left eye preference in bilaterally trained horses was a direct function of their training, we should expect this preference to be consistently weaker than in traditionally trained horses under all circumstances where a person is present, regardless of the activity or relationship to the person. Conversely, if the weaker preference was a result of forming a closer emotional bond to the trainer, we might expect the effect to vary with the social situation.

To resolve this ambiguity directly, we needed to compare the performance of bilaterally trained horses under passive conditions (experiment 2), with their performance under interactive testing. In addition, we were interested to know whether, under interactive testing, training still makes a difference. To answer the latter, we tested both conventionally trained and bilaterally trained horses in an interactive situation: if training is indeed the key factor, we should expect the bilaterally trained horses to show a weaker left eye preference than the conventionally trained ones as they did in the passive test. We report the latter investigation first (as Experiment 3), then use the data for those bilaterally trained horses also tested 


\begin{tabular}{|c|c|c|c|c|}
\hline Group 3 horses & $\begin{array}{l}\text { Laterality } \\
\text { index }\end{array}$ & Group 4 horses & $\begin{array}{l}\text { Laterality } \\
\text { Index }\end{array}$ & \\
\hline $\begin{array}{l}\text { Traditionally } \\
\text { trained }\end{array}$ & & $\begin{array}{c}\text { Bilaterally } \\
\text { trained }\end{array}$ & & \\
\hline Candyman & 1.00 & Bigsy & 0.67 & \\
\hline Francis & 1.00 & Kari & 1.00 & $* * *$ \\
\hline Mary & 1.00 & Ronja & 0.96 & $* * *$ \\
\hline Traum & 1.00 & Wita & 0.92 & $* *$ \\
\hline Frieda & 1.00 & Emily & 0.96 & $* * *$ \\
\hline Gero & 0.75 & Triona & 0.79 & ** \\
\hline Verena & 0.75 & Riska & 0.75 & * \\
\hline Coleen & 1.00 & Ringo & 0.88 & $* *$ \\
\hline Tres Chic & 0.60 & Offe & 0.79 & $* *$ \\
\hline La Belle & 1.00 & Milka & 0.92 & $* *$ \\
\hline La Luna & 1.00 & Baron & 0.92 & $* *$ \\
\hline Heaven & 0.00 & Keira & 0.42 & \\
\hline Wanda & 1.00 & Melissa & 0.83 & $* *$ \\
\hline Momo & 1.00 & & & \\
\hline Elan & 1.00 & & & \\
\hline Indra & 0.33 & & & \\
\hline Sylvester & 1.00 & & & \\
\hline Demi & 1.00 & & & \\
\hline Rhodos & 1.00 & & & \\
\hline Amigo & 0.67 & & & \\
\hline Pan Tau & 1.00 & & & \\
\hline Wiebke & 0.33 & & & \\
\hline Tantieme & 1.00 & & & \\
\hline Amadeus & 1.00 & & & \\
\hline Massimo & 0.50 & & & \\
\hline Komet & 0.67 & & & \\
\hline $\begin{array}{l}\text { left preferent / } \\
\text { total horses }\end{array}$ & $23 / 26$ & & Nov 13 & \\
\hline Binomial Test & $\begin{array}{l}p= \\
0.0001\end{array}$ & & $\begin{array}{l}p= \\
0.0225\end{array}$ & \\
\hline
\end{tabular}

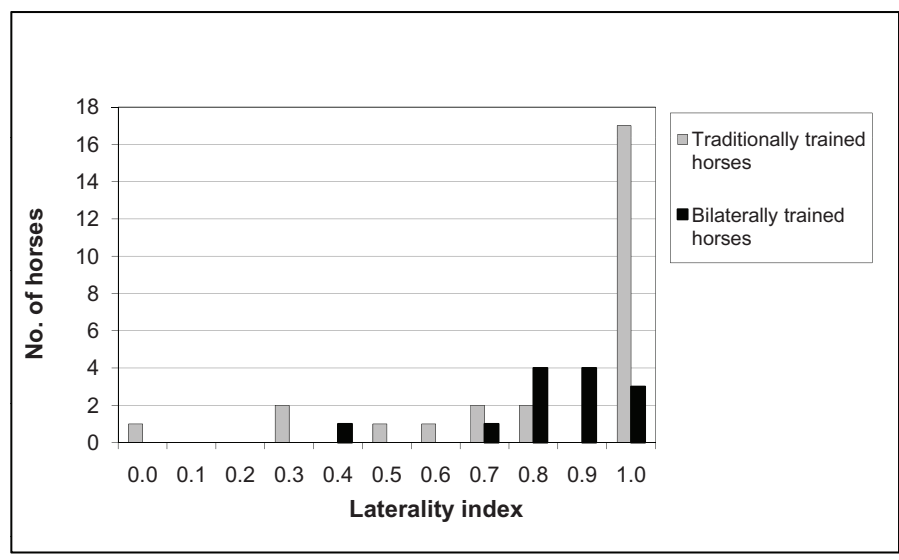

Fig.4: Frequency distribution of laterality indices - interactive test, group 3, traditionally trained horses) and group 4, bilaterally trained horses. (Laterality indices as in Fig. 2)

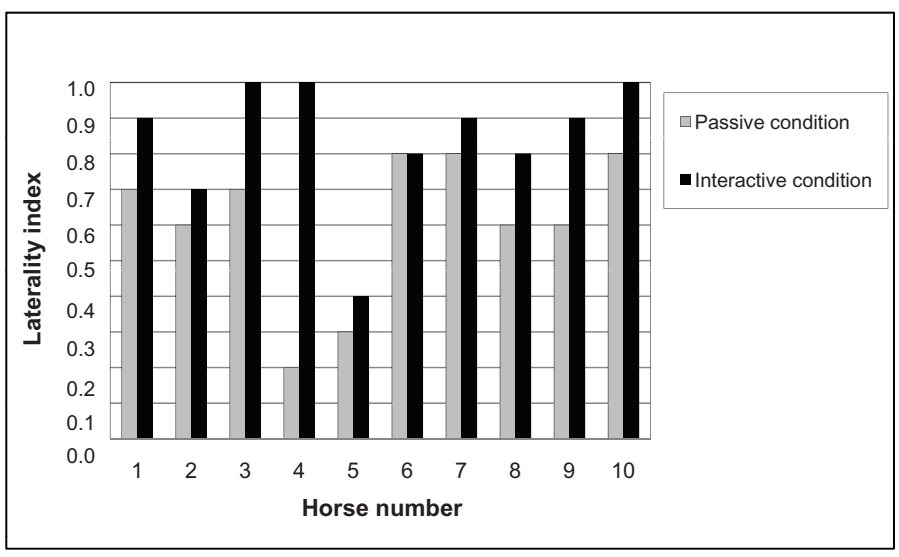

Fig.5: Comparison of laterality indices between passive and interactive situations for 10 horses, all of which were trained bilaterally. (Laterality indices as in Fig. 2)

They were chased by a trainer until they gave specific signals, including turning an ear to the trainer, making the circle smaller, licking and chewing, and lowering the head. The trainer then stopped chasing, turned their back to the horse, and allowed the horse to approach and stand next to them. We noted the direction the horse was travelling prior to approach, and the side of the horse it turned to the trainer as it approached and stood next to the trainer. As the data were taken from another experimental design which had been constructed to examine the behaviour prior to approaching the trainer, there were different numbers of approaches from each horse, ranging from 4 to 6 , with a total of 85 approaches. These horses were not previously familiar with the Roberts technique.

Group 4 was tested using a "hook on" method. The horses were tested in test area 2, in a 15 meter diameter round pen. There they were encouraged to move away from the trainer by the trainer swinging a rope, and then invited to return by the trainer turning his or her back. The trainer alternated the direction (to the left or right) that the horse was sent away, and we recorded the side of the horse it turned to the trainer as it returned and stopped next to the trainer. 8 of these horses were tested on 2 separate occasions with 6 trials to the left, and 6 to the right on each oc-

Group 3 was tested using the "join-up" technique popularised by Monty Roberts (2002). The horses were tested in test area 2, in a 20×20 metre square arena. 
casion, making a total of 24 approaches per horse. 5 horses were tested on only one occasion, with 6 approaches from the left and 6 from the right. Different trainers were used, but all the trainers were known to the horses already. All the horses were familiar with the "hook on" method already.

For both groups, experimenter 1 led the horse into the test area, released it and withdrew. The trainer, experimenter 2 , then interacted with the horse, while the experimenter 1 recorded the data manually and on video tape.

\section{Results}

For group 3, there were insufficient data to analyse the significance of laterality in individual horses, but 23 out of 26 horses positioned themselves more often with the trainer in their left eye (binomial test, $p=$ 0.001 ; see Table 2). In group 4, 12 out of 13 (binomial test, $p=0.003$ ) showed a preference to put the person in the left eye, and 11 of these were significant on an individual level (binomial test, all $p \leq 0.05$; Table 2). One showed a non-significant preference to put the person on the right.

There was no significant difference between the left eye response levels of the two groups (Fig. 4, Mann Whitney U Test, N1=26, N2=13; $U=222.5, p=0.112$ ).

\section{Discussion}

In the interactive situation, we found no significant difference in lateral eye preference between the conventionally trained horses and those trained on both sides. Both groups showed strong preferences for the left eye, regardless of training, test technique or previous experience (Fig. 4). For both groups, the trainers involved were well known to the horses and cared for them and fed them, as well as working with them; there is therefore no reason to suppose that there would be any negative emotion associated with them. This would be consistent with the findings of De Boyer Des Roches et al. (2008) that the left eye preference seems to be connected with both positive and negative emotions, and not necessarily only anxiety and negative emotions.

\section{Experiment 4: Does the social situation of tes- ting, passive or interactive, influence eye-prefe- rence?}

To answer this question, we compared the results of the 10 horses that had taken part in both experiments 2 and 3 . We tested the null hypothesis that there was no difference between the passive and active conditions, so we compared the responses to a known person in the passive condition (experiment 2) and to a known person in the interactive condition (experi- ment 3). Under both conditions the horses had been tested in the same round arena, with which they were already familiar, and by trainers already well known to the horses, who regularly fed and cared for them as well as working with them.

\section{Results}

Comparing the laterality indices of each horse under the two conditions (shown in Fig. 5) with paired tests, there was a significantly higher left eye response under the interactive condition (Wilcoxon matched-pairs signed-ranks test : $\mathrm{W}+=45, \mathrm{~W}-=0, \mathrm{~N}=9, \mathrm{p}=0.004$ ).

\section{Discussion}

Left eye preference is evidently not simply a function of a person being present, but also of the relationship to that person at that time. Fureix et al. (2009) also found a difference in the responses of horses according to the nature of the interaction with a human experimenter, with a passive relationship sometimes eliciting completely different reactions from an active interaction. As the trainers in our experiment were well known to the horses, there is no reason to suppose that the horses would feel any greater emotion or fear connected with that individual under one condition than the other; it seems more likely that the increased left eye preference under the interactive condition is connected to the nature of the interaction. It is also interesting to note that the horse that showed an increased right eye preference in the presence of a passive stranger (Keira), showed an increase in left eye usage in the interactive situation. Furthermore, when horses "hook on" to a human in this type of interactive situation, they consistently display a series of behaviours and body postures connected with relaxation (McDonnell 2004), for example head lowering, licking and chewing, and slowing down (Krueger 2007), and it is widely asserted that hooking on develops the horse's trust, comfort and confidence in the human (Roberts 2002; Brannaman 1997). As the left eye also appears to be the "rapid reaction" eye (Austin and Rogers 2007), we would suggest that the left eye may be preferred for the object or animal to which the horse wants to be able to react quickly: which might be a potential threat or predator, but could also be a herd mate. This idea will be developed further in the general discussion.

\section{General Discussion}

In all these experiments, there was a robust tendency for most horses to prefer consistently to use the left eye for viewing the person or the environment. In a very few horses, that preference was the reverse in direction, but equally consistent. 48 of the 55 horses 
showed a left eye preference, 5 showed a right eye preference, 1 showed no preference and 1 changed preference under different conditions. The population preference to use the left eye to observe a person, or in the absence of a person to observe the wider environment, was statistically significant for all groups in every experimental condition, bar a single condition of one experiment where the same trend was nonsignificant.

These findings are consistent with some results of past studies, including studies of other vertebrate species. Cantalupo et al. (1995) have shown a preference in fish, and Rogers et al. (1994) in small-eared bushbabies, to view a potential predator with the left eye; a similar tendency has been found in toads (Lippolis et al. 2002) and primates (Nedellec-Bienvenue and Blois-Heulin 2005, Chapelain and Blois-Heulin 2009). De Boyer Des Roches et al. (2008) found that horses prefer the left eye for viewing objects with both positive and negative association but the right eye for neutral objects. Larose et al. (2006) found a correlation between the emotionality of the horse and its tendency to use the left eye to view a novel object, with the right eye being used more often by horses with a lower emotionality index. They suggest that the use of the respective eye is bound to the individual's perception of specific situations, and that the choice of eye is governed by that horse's character and its assessment of the environment. Consistent with this interpretation, Austin and Rogers (2007) found that horses were more reactive to a frightening stimulus when it was presented on the left. The flight distance was greater when the stimulus was presented first on the left than when it was presented first on the right. Additionally, Rogers (2000) found that chicks, and Lippolis (2002) found that toads are also more reactive to predators perceived with the left eye.

It is interesting that the horses in our experiment 1 preferred the left eye under the "neutral" condition to view the wider area, while in the De Boyer Des Roches et al. (2008) study the horses preferred the right eye for a "neutral" object. However, these apparently contradictory results may, in fact, reflect the same underlying trait. If the left eye is preferred for evaluation and assessment, we would expect it to be the preferred eye for observing whichever object or area is perceived to have the greater need for analysis; those horses choosing to view a neutral object with the right eye may rather be choosing to evaluate the broader environment with the left eye. Taking into account the findings of Austin and Rogers (2007), that most horses react more strongly to a frightening stimulus on the left, it could be that most horses prefer to use the left eye for object or scenarios where they feel they may have a need to react quickly. The strong population laterality we and others have found could have a survival advantage for a prey animal, in that this could help synchronising the herd and im- prove flight reaction, as has been discussed for different fish species (Sovrano et al.1999). Ghirlanda et al. (2004) propose that brain and behavioural lateralization may have evoloved under "social" selection pressures and evidence for lateralisation in response to social stimuli has been found in chicks (Vallortigara and Andrews 1991) and quails (Zucca and Sovrano 2008). While our work has so far been restricted to eye preference, it would be interesting in a further study to compare the level of emotionality under different conditions in interaction with people, and see whether emotionality correlates with degree of lateral preference.

We found a clear difference when a stranger was present but passive, between the traditionally trained horses and those trained on both sides, with the traditionally trained horses showing a stronger left eye preference. This difference disappeared in the interactive situation, when both traditionally and bilaterally trained horses showed a similar ratio of left eye to right eye preferences and the same average laterality index. Moreover, for horses tested under both conditions there was a significantly higher left eye preference in the interactive condition. While it could be argued that the training might have affected the lateralization of fear reactions or responses to novelty, in that case we would expect the effect to be consistent for horses trained in a particular style. Thus the bilaterally trained horses would be expected to show a consistently weaker preference than the traditionally trained groups. In fact, the difference between the groups disappeared in the interactive condition. We therefore suspect that under passive conditions, especially with a conventionally trained horse, the human elicits responses comparable to those shown in other studies towards inanimate novel objects. In contrast, when interacting with the horse, the human is perceived socially regardless of the horse's training history, eliciting consistent reactions.

We suggest that the explanation for the populationlevel laterality effects may be linked to the speed of response that is required in different situations. At present, it is unknown how the members of a group of horses communicate with each other when in flight, that is to say how the group can maintain a close formation and gallop at full speed apparently as almost one unit. One proposal is that the actions of a herd leader are passed very quickly through the herd in a sort of "ripple effect" which the herd members instinctively follow, as has already been proposed in birds (Eftimie et al. 2007). If the left visual field is indeed more reactive, as suggested by Austin and Rogers (2007), left-side vision may be preferred in such situations. We would therefore suggest that the left eye may be preferred for whatever object, scenario, person or animal, to which the horse needs to respond quickly or give its greater attention at that moment. That need may be derived from a perception of the 
object or situation as a potential threat, or out of a perception of it being an individual the horse would wish to cooperate with or respond to quickly. Further research on horse to horse interactions will be needed to investigate this suggestion.

The evidence from these experiments suggests that the horse's general preference to have people on the left is not simply a function of habit and training, but rather it is connected with the horse's emotions and perceptions. This has important implications for the practical situation, and the full context of the left preference needs to be considered in the training situation. In future research it would be interesting to investigate how the left eye preference develops by testing young horses at different ages, and to discover whether there is any correlation between strength of laterality and the rank of a horse in the herd hierarchy. These would give further clues as to the significance of lateralisation and how it might relate to the horse's cognitive functions.

In summary, we can draw three broad conclusions. Firstly, that horses appear to prefer to keep "high priority" stimuli in one visual field (the left, for most horses); secondly, that when interacting with a human tester, the tester appears generally to be the highest priority for the horse, and this is not affected by the horse's training; and finally, when a human is present but passive, the human is a priority for conventionally-trained horses who regard them as a risk, but less for the bilaterally-trained horses, apparently because they are more comfortable in the presence of humans.

\section{Acknowledgements}

We would like to thank Christianne Torkelsen for her work in testing the group 1 horses. We would also like to thank all the horse owners who allowed their horses to take part in the tests, and all the helpers for their time and efforts during the testing procedures, in particular Petra Studeny, for her invaluable help in collecting data, organising the testing and taking part in the test procedures, Hal Rock for his tremendous help and support, and the many volunteers who kindly gave their time and energy to assist in this research. We also thank Knut Krueger for his help with the statistical analysis, and Birgit Flauger for her valuable suggestions and input.

\section{References}

Austin NP, Rogers LJ (2007) Asymmetry of flight and escape turning responses in horses. Laterality 12(5):464-474

Basile M, Boivin S, Boutin A, Blois Beulin C, Hausberger M, Lemasson A (2009) Socially dependent auditory laterlity in domestic horses (Equus caballus). Animal Cognition, 12:611-619

Bisazza A, Rogers L, Vallortigara G (1998) The origins of cerebral asymmetry: A review of evidence of behavioural and brain lateralization in fishes, amphibians, and reptiles. Neuroscience and Biobehavioral Reviews 22:411-426

Brannaman, B (1997) Groundwork: The First Impression. Rancho Deluxe Design, California

Cantalupo C, Bisazza A, Vallortigara G (1995) Lateralisation of predator-evasion response in teleost fish (Girardinus falcatus). Neuropsychologia 32:1637-46

Chapelain AS, Blois-Heulin CL (2009) Lateralization for visual processes: eye preference in Campbell's monkeys (Cercopithecus c. campbelli). Animal Cognition 12(1): 11

De Boyer Des Roches A, Richard-Yris M-A, Henry S, Hausberger M (2008) Laterality and emotions: visual laterality in the domestic horse (Equus caballus) differs with objects' emotional value. Physiology and Behaviour 94(3):487-90

Deng C, Rogers LJ (1997) Differential contributions of the two visual pathways to functional lateralization in chicks. Behavioual Brain Research 87(2):173-182

Eftimie R, de Vries G, Lewis MA (2007) Complex spatial group patterns result from different animal communication mechanisms. PNAS 104:69746979

Fureix C, Jego P, Sankey C, Hausberger M (2009) How horses (Equus caballus) see the world: humans as significant "objects". Animal Cognition. 12:643-654

Hanggi EB (1999) Interocular transfer in horses (Equus caballus). Journal of Equine Veterinary Science 19(8):518-524

Humle T, Matsuzawa T (2009). Laterality in hand use across four tool-use behaviors among the wild chimpanzees of Bossou, Guinea, West Africa. American Journal of Primatology 70:40-48

Krueger K (2007) Behaviour of horses in the 'round pen technique'. Applied Animal Behaviour Science 104:162-170

Larose C, Richard-Yris M-A, Hausberger M (2006) Laterality of horses associated with emotionality in novel situations. Laterality 11 (4):355-367

Lippolis G, Bisazza A, Rogers LJ, Vallortigara G (2002). Lateralization of predator avoidance responses in three species of toads. Laterality 7:163183

Lonsdorf, EV, Hopkins, WD (2005). Wild chimpanzees show population-level handedness for tool use. PNAS 102:12634-12638

Marchant, LF, \& McGrew, WC (1991) Laterality of function in apes: a meta-analysis of methods. Journal of Human Evolution 21:425-438

McDonnell SM (2003) The Equid Ethogram: A Practi- 
cal Field Guide to Horse Behavior. Eclipse Press, Lexington, Kentucky

McGreevy PD, Rogers LJ (2004) Motor and sensory laterality in thoroughbred horses. Applied Animal Behaviour Science 92:337-352

Miller RM, Lamb R (2005) The revolution in horsemanship and what it means to mankind. The Lyons Press, Guilford, Connecticut

Murphy J, Arkins S (2008) Facial hair whorls (trichoglyphs) and the incidence of motor laterality in the horse. Behavioural Processes 79(1):7-12

Murphy J, Sutherland A, Arkins S (2004) Idiosyncratic motor laterality in the horse. Applied Animal Behaviour Science 91:297-310

Nedellec-Bienvenue D, Blois-Heulin C (2005) Eye Preferences in Red-Capped Mangabeys. Folia Primatologica 76:234-237

Podhajsky A (1967) The Complete Training of Horse and Rider. The Sportsman's Press.

Pfungst O (1911) Clever Hans (the Horse of Mr. Von Osten). Henry Holt, New York

Roberts M (2002) From My Hands to Yours. Lessons from a Lifetime of Training Companionship Horses. Monty and Pat Roberts Inc., Solvang

Robins A, Rogers LJ (2004) Lateralized prey-catching responses in the cane toad, Bufo marinus: analysis of complex visual stimuli. Animal Behaviour 68:767-775

Rogers LJ , Ward JP, Stafford D (1994) Eye domi- nance in the small-eared bushbaby, Otolemur garnettii. Neuropsychologia 32:257-264

Rogers LJ, (2000) Evolution of hemispheric specialisation: Advantages and disadvantages. Brain and Language 73:236-253

Sovrano VV, Rainoldi C, Bisazza A, Vallortigara G (1999) Roots of brain specializations: preferential left-eye use during mirror-image inspection in six species of teleost fish. Behavioural Brain Research 106:175-180

Steinbrecht G (1886) Das Gymnasium des Pferdes. Döring Verlag, Potsdam

Vallortigara G, Rogers, LJ (2005) Survival with an asymmetrical brain: Advantages and disadvantages of cerebral lateralization. Behavioral and Brain Sciences 28:575-589

Vallortigara G, Andrew RJ (1991) Lateralization of response by chicks to change in a model partner. Animal Behaviour 41:187-194

Ward JP, Hopkiss WD (1993) Primate Laterality: Current Behavioural Evidence of Primate Asymmetries. Springer-Verlag $\mathrm{GmbH}$, Berlin

Williams DE, Norris BJ (2007) Laterality in stride pattern preferences in racehorses. Animal Behaviour 74:941-950

Zucca P, Sovrano VA (2008) Animal lateralization and social recognition: quails use their left visual hemifield when approaching a companion and their right visual hemifield when approaching a stranger. Cortex 44:13-20 